\title{
The Application of the Grey Neural Network in the Deflection Control of PC Rigid Frame Continuous Box Girder Bridges
}

\author{
Lifeng Wang, Hongwei Jiang, and Dongpo He*
}

Northeast Forestry University, Harbin 150040, China

\begin{abstract}
Deflection control is the crucial procedure in construction control of cantilever prestressed concrete continuous girder bridge. This paper summarizes the advantages of Grey theory's poor information processing and abilities of Neural Network's self-learning and adaption, and the combinational algorithm of grey Neural Network is applied to the prestressed concrete bridge cantilever construction control process. Firstly, GM $(1,1)$ model and BP artificial Neural Network algorithm to predict the elevation of construction process are introduced respectively. In addition, the elevation prediction model of rigid-framed-continuous girder bridge is established. By practicing in the construction control project of LongHua Bridge, the method is testified to be feasible. The results indicate that, the combinational algorithm of Gray Neural Network to predict the construction elevation has higher reliability and accuracy which can be an effective tool of construction control for the same type bridges.
\end{abstract}

Keywords: BP artificial neural network, Grey theory, GM $(1,1)$ model, Rigid-framed-continuous girder bridge.

\section{INTRODUCTION}

Deflection control is one of the most difficult tasks in cantilever bridge construction [1-2]. It is necessary to control each cantilever segment's deflection so as to ensure the safety and quality of bridge construction and make the actual status of bridge to meet the design requirements.

Finite element method is the most extensive used analysis method of bridge structure which can complete deflections theoretical calculation and analysis in construction process. However, deflection errors are existed in each construction stage and affected by many factors with certain randomness and nonlinear. Therefore, it is necessary to use other methods to predict construction deflection. Currently employed predictive control analysis methods mainly include Kalman method, Gray system theory, Least-square method and Neural Network forecasting method. The advantages of gray prediction theory are that it can find the inherent regularity and give prediction results with insufficient data. But there will be much error when dealing with discrete larger data. Neural network prediction algorithm has strong nonlinear information processing capability, it can make up for the inadequacy of gray theory, and gray theory can reduce the sample quantity to meet the requirement of Neural Network algorithm [3]. This paper combines with Gray theory and Neural Network theory, and establishes gray forecasting model of Neural Networks for rigid-framed-continuous girder bridge. Furthermore, the feasibility of this method is verified via combining the advantages of these two algorithms advantages and measured data.

\section{GRAY GM(1,1) MODEL}

\subsection{Model Establishment}

Gray model is a mathematical model which can deal with the random discrete raw data impacted by noise pollution. The most commonly used Gray GM $(1,1)$ model will make the stochastic primitive time sequence accumulated according to time, the present laws of the newly formed time series can approximate the solution through an order linear differential equations. Its corresponding modeling steps are [4]:

1) The original sequence:

$x^{(0)}=\left\{x^{(0)}(1), x^{(0)}(2), x^{(0)}(3), \ldots, x^{(0)}(N)\right\}$

Once accumulation:

$x^{(1)}=\left\{x^{(1)}(1), x^{(1)}(2), x^{(1)}(3), \ldots, x^{(1)}(N)\right\}$

Among them:

$x^{(1)}(t)=\sum_{k=1}^{t} x^{(0)}(k)$

2) Tectonic accumulative matrix $B$ and constant vector $\mathrm{Y}_{\mathrm{N}}$ :

$B=\left[\begin{array}{cc}-\frac{1}{2}\left(x^{(1)}(1)+x^{(1)}(2)\right) & 1 \\ -\frac{1}{2}\left(x^{(1)}(2)+x^{(1)}(3)\right) & 1 \\ \cdots \\ -\frac{1}{2}\left(x^{(1)}(N-1)+x^{(1)}(N)\right) & 1\end{array}\right]$
$Y_{N}=\left[x_{1}^{(0)}(2), x_{1}^{(0)}(3), \ldots x_{1}^{(0)}(N)\right]^{T}$ 
3) Solving gray parameters â with least-square method:

$\hat{a}=[a, u]^{T}=\left(B^{T} B\right)^{-1} B^{T} Y_{N}$

4) Bring the gray parameters into time functions, calculate the difference $q^{(0)}(t)$ between $x^{(0)}(t), \hat{x}^{(0)}(t)$ and relative error $e(t)$ :

$$
\begin{aligned}
& \hat{x}^{(1)}(t+1)=\left[x^{(0)}(1)-\frac{u}{a}\right] e^{-a t}+\frac{u}{a} \\
& \hat{x}^{(0)}(t+1)=-a\left[x^{(0)}(1)-\frac{u}{a}\right] e^{-a t} \\
& \hat{x}^{(0)}(t+1)=\hat{x}^{(1)}(t+1)-\hat{x}^{(1)}(t) \\
& q^{(1)}(t)=x^{(0)}(t)-\hat{x}^{(0)}(t) \\
& e(t)=\frac{q^{(0)}(t)}{x^{(0)}(t)}
\end{aligned}
$$

\subsection{Precision Test}

After the model established, in order to ensure the gray GM $(1,1)$ model has high accuracy and satisfies the demand of practical engineering, its relative error, mean square error ratio and small error probability generally are needed to be inspected. Inspection methods are as follows:

The raw data variance:

$S_{1}^{2}=\frac{1}{n} \sum_{k=1}^{n}\left[x^{(0)}(k)-\bar{x}\right]^{2}$

The residual variance:

$S_{2}^{2}=\frac{1}{n-1} \sum_{k=2}^{n}\left[e^{(0)}(k)-\bar{e}\right]^{2}$

The posterior variance ratio: $\mathrm{C}=\mathrm{S} 2 / \mathrm{S} 1$

Small error probability:

$$
P=\frac{P}{\left\{\left|e^{(0)}(k)-\bar{e}\right|<0.6745 S_{1}\right\}}
$$

Among them, $\bar{x}$ is original series mean; $\bar{e}$ is error mean. Usually, the parameter of $\mathrm{C}$ is smaller and $\mathrm{P}$ is bigger, the precision of the model is higher. Judging criteria is shown in Table 1 [5, 6].

Table 1. Judging criteria.

\begin{tabular}{|l|l|l|}
\hline Model precision grades & P & C \\
\hline \hline Band (Excellent) & $0.95 \leq \mathrm{P}$ & $\mathrm{C} \leq 0.35$ \\
\hline Band (Qualified) & $0.80 \leq \mathrm{P}<0.95$ & $0.35<\mathrm{C} \leq 0.5$ \\
\hline Band (Reluctantly) & $0.70 \leq \mathrm{P}<0.80$ & $0.5<\mathrm{C} \leq 0.65$ \\
\hline Band (Unqualified) & $\mathrm{P}<0.70$ & $0.65<\mathrm{C}$ \\
\hline
\end{tabular}

\section{BP NEURAL NETWORK MODEL}

BP algorithm is of a typical algorithm artificial Neural Network, its main structure is error response propagation network model with input layer, hidden and output layer. Each neuron of adjacent layers is connected, the output of previous layer unit cannot feedback to forward layer and there are no connections within the same layer.

BP Neural Network can establish global nonlinear mapping relations between input variables and output variables of network through self-learning of testing sample. BP algorithm lies in using the error output to estimate the error of former layer, then to estimate the error of more former layer with this error, so a layer of reverse handed down, all the errors of other layers will be got. The progress that the errors showed in output layer transfer to input layers along with the opposite direction of input layers will be formed. Therefore, it is called error backward algorithm, shorted for BP (Backpropagation Neural Network) algorithm. BP Neural Network is suitable for bridge as a system with nonlinear forecast and control. BP Neural Network includes input layer, hidden layer and output layer. Hidden layer can be one layer or several layers. The common used three layer model of BP Neural Network is showed in Fig. (1).

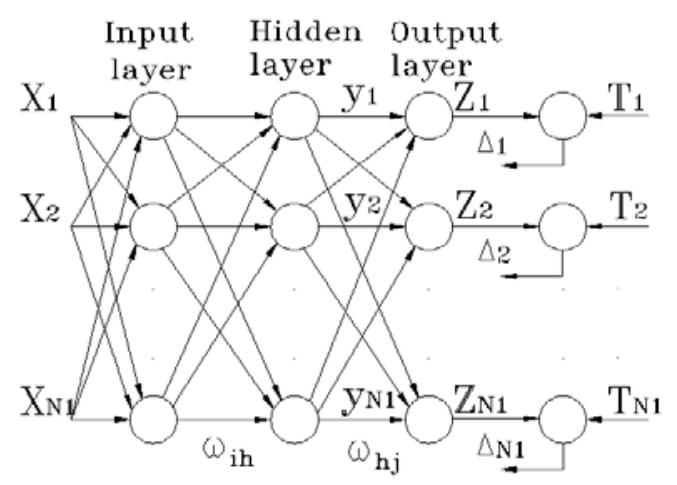

Fig. (1). Three-layered BP neural network model.

\section{GRAY NEURAL NETWORK MODEL}

Gray neural network is divided into parallel type, tandem type and embedded type according to the data processing features of Gray model and Neural Network [7-9]. Tandem type gray neural network establishes GM $(1,1)$ model through getting different elements from the original data, the gray forecasting results will be as input data of neural network. The combination forecasting results will be obtained via the neural network model. Embedded Gray Neural Network model will do the neural network analysis after the original data is handled by grey layer, and the prediction results will be output through albino layer.

Parallel Gray Neural Network model will deal and predict the data respectively through grey $\operatorname{GM}(1,1)$ model and Neural Network model, then to combine the forecast results, the revised weighted prediction can be as the final prediction result.

$$
\hat{y}_{t}=k_{1} \hat{y}_{1 t}+k_{2} \hat{y}_{2 t}(\mathrm{t}=1,2, \ldots, \mathrm{N})
$$


Table 2. Sample data of gray neural network.

\begin{tabular}{|c|c|c|c|c|c|}
\hline Casting segment & Temperature (C) & Cantilever length (m) & Section height (m) & Self-weight(kN) & Deflection (m) \\
\hline \hline $1 \#$ & 20 & 8.75 & 2.56 & 806.879 & 0.004 \\
\hline $2 \#$ & 23 & 12.5 & 2.56 & 812.214 & 0.002 \\
\hline $3 \#$ & 22 & 17 & 2.609 & 871.168 & 0.001 \\
\hline $4 \#$ & 18 & 21.5 & 2.731 & 949.944 & 0.001 \\
\hline $5 \#$ & 20 & 26 & 3.154 & 1039.717 & 0.003 \\
\hline $6 \#$ & 22 & 30.5 & 3.447 & 1147.062 & 0.003 \\
\hline $7 \#$ & 19 & 35 & 3.792 & 1272.436 & 0.002 \\
\hline $8 \#$ & 17 & 39.5 & & \\
\hline
\end{tabular}

Table 3. Predicted results.

\begin{tabular}{|c|c|c|c|c|c|c|c|}
\hline \multirow{2}{*}{ Casting segment } & \multirow{2}{*}{$\begin{array}{c}\text { Measured } \\
\text { deflection }\end{array}$} & \multicolumn{2}{|c|}{ GM(1, 1) model } & \multicolumn{2}{|c|}{ BP Neural Network } & \multicolumn{2}{c|}{ Gray Neural Network } \\
\cline { 3 - 8 } & & Prediction & Error & Prediction & Error & Prediction & Error \\
\hline \hline $9 \#$ & -0.006 & 0.006 & 0.0051 & $15 \%$ & 0.0061 & $2 \%$ & 0.00605 \\
\hline $10 \#$ & 0.022 & 0.022 & 0.0195 & $11 \%$ & 0.020 & $10 \%$ & 0.02187 \\
\hline
\end{tabular}

$\hat{y}_{t}$ is weighted array predictive value, $\mathrm{N}$ is the total number of the forecast data; $\hat{y}_{1 t}$ and $\hat{y}_{2 t}$ are respectively predictive value Grey model and Neural Network; $K_{1}$ and $K_{2}$ are the weighting coefficients of the two kinds of prediction model.

First, the prediction accuracy of two models is defined by "effective degrees" concept.

$A_{t}=1-\left|\frac{y_{t}-\hat{y}_{t}}{y_{t}}\right|$

Mean $\mathrm{E}$ and average variance $\sigma$ of the forecasting precision sequence is:

$E=\frac{1}{N} \sum_{t=1}^{N} A_{t}, \quad \sigma=\frac{1}{N}\left[\sum_{t=1}^{N}\left(A_{t}-E\right)^{2}\right]^{\frac{1}{2}}$

Effective degree of the forecasting is:

$S=E(1-\sigma)$

Calculate the effective degree $S_{1}$ and $S_{2}$ of Gray GM (1, 1) model and Neural Network, the weighting coefficients $K_{1}$ , $\mathrm{K}_{2}$ can be got after the normalized the two degrees:

$k_{i}=\frac{S_{i}}{\sum_{j=1}^{2} S_{j}}$

This paper adopts parallel Gray Neural Network and comprehensive utilization of the forecasting information provided by the two methods, so as to reduce randomness and increase the prediction accuracy.

\section{ENGINEERING EXAMPLE}

\subsection{Project Summary}

Longhua Bridge is located in the city of SongYuan, JiLin province. The main bridge of the bridge adopts 65 $\mathrm{m}+5 \times 100 \mathrm{~m}+65 \mathrm{~m}$, seven hole one unit with prestressed concrete continuous box girder. The main piers of the main bridge adopt double thin-wall pier, and the left $3 \#$ pier and girder are rigidly connected. The length of LongHua Bridge is $2158 \mathrm{~m}$, and the plan of the calculation model of the structural analysis is showed in Fig. (2).

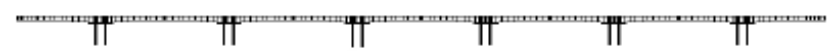

Fig. (2). Analysis model of bridge structure.

\subsection{The Prediction of Gray Neural Network}

By using the gray recursive predictive model GM $(1,1)$ and rolling forecasting method, the deflection value of next stage can be predicted according to the known construction deflection data. After the forecasting result is obtained, removing the first element of the known deflection sequence, the forecasted result will be as the known condition in the next prediction. The predicted results of Gray GM $(1,1)$ model are showed in Table 2.

The BP Neural Network adopts former 8 casting cantilever segments as training sample data. Because of the cantilever rigid-framed-continuous girder bridge is influenced by many factors, the relatively sample data such as temperature, cantilever length (the distance between every free surface of each stage in cantilever construction and the centerline of 
block 0 \#) and self-weight and free surface's height of the beam segment are the input data of Neural Network [10]. The former eight casting segments will be as a target sequence, the deflection of $9 \#$ and $10 \#$ segment during construction as the output of predictive value.

This paper adopts the BP Neural Network model as 4-7-1 structure, because the units and orders of magnitude among the input data are big, the data need to be normalized, the input variables processed is $\mathrm{Y}_{\mathrm{i}}$ :

$Y_{i}=a+b \times \frac{X_{i}-X_{\min }}{X_{\max }-X_{\min }}$

Among them: $a=0.1, b=0.8$.

The training sample data of BP Network are showed in Table 2.

The predicted value of elevation for segment $9 \#$ and $10 \#$ cantilever construction is carried out by the methods of Gray GM $(1,1)$ model, Neural Network model and Gray Neural Network model are shown in Table $\mathbf{3}$.

\section{CONCLUSION}

Gray Theory and Artificial Neural Network are all data processing algorithms, which have little physical significance. So they can be used widely in industry and engineering fields. This paper deals with the deflection control of rigid-framed-continuous girder bridge during cantilever construction process. The results show that prediction error can meet the engineering requirements and well reliability by the combined model.

BP Neural Network has the ability of approaching to arbitrary function, but its disadvantage is slower training speed. Grey forecast method can get the utmost out of limited data, which has no need of statistical features analysis. Parallel Gray Neural Network model combines the advantages of two methods. The predicted results are superior to that brought by any single method.

Gray Neural Network prediction method is easy to carry out, precise and high reliability, which has a high practical value in cantilever construction control of rigid-framedcontinuous girder bridge.

\section{CONFLICT OF INTEREST}

The authors confirm that this article content has no conflict of interest.

\section{ACKNOWLEDGEMENTS}

This research was supported by the Fundamental Research Funds for the Central Universities (No. 2572015ET01) funded by Ministry of Finance, Education of the People's Republic of China and Heilongjiang Postdoctoral Grant (No. LBH-Z14013) funded by Heilongjiang provincial government.

\section{REFERENCES}

[1] E. Mamdouh, G. Amin, and G. Ramez B, "Deflection control of prestressed box girder bridges", Journal of Bridge Engineering, vol. 19, no. 5, May 1, 2014.

[2] F. Guo, Y. Q. Yang, and S. Q. Huang, "Research on deflection and cracking of prestressed concrete continuous girder bridge", Advanced Materials Research, vol. 838-841, pp. 1014-1017, 2014.

[3] J. L. Yuan, L. Zhong, and X. Y. Li, "The Research and Development of Grey Neural Network", Journal of Wuhan University of Technolog, vol. 31, no. 3, pp. 91-93, February 2009.

[4] D. C. Chi, Y. F. Tang, T. Gu, M. Yu, Z. Li, and Z. Z. Ma, "Prediction of irrigation water use using parallel gray neural network", Transactions of the CSAE, vol. 25, no. 5, pp. 26-29, May 2009.

[5] J. Z. Zhang, J. X. Zhang, and F. Zhao, "Application of Gray Forecast in the Deformation Analysis of Tunnel Project", Journal of Xihua University (Natural Science edition), vol. 29, no. 1, pp. 103-106, January 2010.

[6] Q. C. Meng, X. Qi, Q. Li, and Y. Z. Bu, "Parameter identification of long-span cable-stayed bridge based on grey-neural network", Journal of Southwest Jiaotong University, vol. 44, no. 5, pp. 704709, October 2009.

[7] Y. P. Wu, W. F. Teng, and Y. W. Li, "Application of grey-neural network model to landslide deformation prediction", Chinese Journal of Rock Mechanics and Engineering, vol. 26, no. 33, pp. 632-636, March 2007.

[8] C. D. Golghate and M. S. Pawar, "Development of Green Supply Chain for Plastic Films Manufacturing Industries in India: Ranking of Challenges using Analytic Hierarchy Process", Advances in Industrial Engineering and Management, vol. 3, no. 4, pp. 45-58, 2014. doi:10.7508/AIEM-V3-N4-45-58

[9] J. Ping, "Application of grey theory and wavelet neural network in slope displacements prediction", Journal of Applied Sciences, vol. 13, no. 21, pp. 4764-4768, 2013.

[10] M. Lei, "Application of BP Neural Network on Construction Control of Long Span Steel Box Girder Cable-stayed Bridge", Master's thesis, Southwest Jiaotong University, Chengdu, Sichuan, China, July 1, 2008.

Received: July 4, 2014

Revised: October 7, 2014

Accepted: December 23, 2014

(C) Wang et al.; Licensee Bentham Open.

This is an open access article licensed under the terms of the (https://creativecommons.org/licenses/by/4.0/legalcode), which permits unrestricted, noncommercial use, distribution and reproduction in any medium, provided the work is properly cited. 